\title{
0 governo e a mídia na configuração do macroambiente para os biocombustíveis líquidos no Brasil*
}

\author{
Edson Talamini** \\ Homero Dewes***
}

Sumário: 1. Introdução; 2. Planejamento estratégico: a análise do macroambiente; 3 . Aspectos da relação entre governo e mídia; 4. Método e procedimentos; 5. Resultados; 6. Conclusões.

Summary: 1. Introduction; 2. Strategy Planning: analysis of the macro-environment; 3 . Aspects of the relation between the government and the media; 4. Method and procedures; 5 . Results; 6 . Conclusions.

Palavras-chave: escaneamento ambiental; planejamento estratégico; mineração em textos; dimensões macroambientais; palavras-d.

KEY WORDS: environmental scanning; strategic planning; text mining; macro-environmental dimensions; d-words.

Este artigo identifica as dimensões nas quais o governo e a mídia do Brasil têm configurado o macroambiente para os biocombustíveis líquidos ao longo do tempo e testam a existência de similaridade entre esses meios de expressão da sociedade na configuração do macroambiente. Para atingir o objetivo, foi realizada uma pesquisa documental a partir das notícias sobre o tema "biocombustíveis líquidos" veiculadas pela mídia escrita e de documentos oficiais do governo brasileiro tratando do mesmo tema. Foram coletados documentos textuais em formato eletrônico para um período de 10 anos (1997 a 2006). A extração do conhecimento dos textos em

\footnotetext{
* Artigo recebido em fev. e aceito em dez. 2008. Este artigo é resultado de pesquisa apoiada pela Finep/Fapergs/Projeto Estruturante em Agroenergia — RS.

** Doutor em agronegócios pela Universidade Federal do Rio Grande do Sul (Cepan/UFRGS), professor da Faculdade de Administração, Ciências Contábeis e Economia (Face), da Universidade Federal da Grande Dourados (UFGD). Endereço: Rua Quintino Bocaiúva, 2250 - Jardim Girassol _ CEP 79824-140, Dourados, MS, Brasil. E-mail: edsontalamini@terra.com.br.

$* * *$ Doutor em biologia pela University of California, Los Angeles, professor do Departamento de Biofísica, do Instituto de Biociências e do Programa de Pós-Graduação em Agronegócios - Cepan, da Universidade Federal do Rio Grande do Sul (UFRGS). E-mail: hdewes@ufrgs.br.
} 
formato eletrônico foi realizada por meio de mineração em textos, aplicando-se uma estrutura de análise específica contendo as dimensões macroambientais e suas respectivas "palavras-d", que foram definidas a partir das palavras mais frequentes nas áreas do conhecimento relacionadas a cada dimensão. Os resultados indicam que a configuração do macroambiente para os biocombustíveis líquidos pela mídia e pelo governo difere quanto ao uso das dimensões macroambientais. A configuração do macroambiente também apresentou variações ao longo do período analisado, tanto na mídia quanto no governo. Testes de similaridade, aderência e homogeneidade confirmam a existência de diferenças entre a mídia e o governo. As implicações dos resultados encontrados para a atividade de escaneamento macroambiental destinado ao planejamento estratégico das organizações em geral e dos biocombustíveis líquidos em particular são discutidas.

\section{Government and media in the configuration of the macroenvironment for liquid biofuels in Brazil}

This article identifies the dimensions in which the Brazilian government and the media have shaped the macroenvironment for liquid biofuels through time, and tests the similarities among these means of expression of the society in the macroenvironmental setting. It conducts a documental research of the news on liquid biofuels published by the press and of official documents of the Brazilian government about the same subject. Electronic written documents covering a 10-year period (1997 to 2006) were collected and the information from them was extracted through text mining applying a specific analytical framework containing the macroenvironmental dimensions and their respective 'd-words', which were defined from the most frequent words in the knowledge areas related to each dimension. The results show that the configuration of the macroenvironment for liquid biofuels differs in the press and in the government. The setting of the macroenvironment also presented variations throughout the period. Similarity, adherence and homogeneity tests confirmed the existence of differences between the press and the government. The article discusses the implications of the results for the activity of macroenvironmental scanning related to the strategic planning of the organizations in general and of the liquid biofuels specifically.

\section{Introdução}

O aquecimento global atribuído à queima de combustíveis fósseis parece ser um dos principais vetores da emergência contemporânea dos biocombustíveis líquidos como fonte renovável de energia. Contudo, existem evidências que sugerem a existência de outros vetores, verificáveis nos diferentes campos de percepção e expressão das sociedades, cuja compreensão pode ser relevante 
para a afirmação de mercados regionais ou internacionais de biocombustíveis líquidos, como o etanol e o biodiesel. A configuração do macroambiente para a emergência dos biocombustíveis líquidos pode estar expressa nas dimensões macroambientais, sob as quais os biocombustíveis líquidos são enquadrados pelo governo e pela mídia de um determinado país. A configuração do macroambiente para os biocombustíveis líquidos em cada país pode ser definida a partir das interações entre a mídia e o governo, como meios de expressão social, e das interações deles com a audiência.

Ao monitorarem o macroambiente para realizarem seus planejamentos estratégicos, as organizações identificam as dimensões macroambientais sob as quais os biocombustíveis líquidos estão enquadrados e conduzem suas estratégias de investimento de acordo com os sinais emitidos por esses meios de expressão social. Assim, tanto o governo quanto a mídia desempenham papel fundamental no suprimento de informações para a tomada de decisão no planejamento estratégico das empresas. O governo pela condução e orientação das políticas públicas nas diferentes áreas de atuação do Estado e a mídia pelo importante papel que desempenha na disseminação das informações, em especial a mídia escrita, considerada principal fonte de informação para muitos executivos.

Embora sejam meios de expressão social distintos, governo e mídia podem apresentar relações de proximidade entre si. Os ganhos destas relações podem ser positivos para ambas as partes. Para o governo, a mídia pode ser um veículo formidável para atingir uma ampla parcela da população e divulgar suas ações. Para a mídia, o governo pode ser uma fonte interessante e contínua de informações, sempre úteis para manter a característica informativa da mídia. No entanto, nem sempre as relações entre governo e mídia são harmônicas. A possibilidade de um exercer influência sobre o outro pode resultar em uma relação de medição de forças para determinar quem possui maior poder, podendo influenciar ao invés de ser influenciado.

Na última década, o Brasil vem experimentando uma nova onda de investimentos na produção de biocombustíveis líquidos. Novos investimentos vêm sendo feitos ao longo das cadeias produtivas, desde o desenvolvimento de plantas, passando pela ampliação das áreas de plantio, instalação de novas plantas fabris até o desenvolvimento de novas tecnologias de consumo voltadas para os biocombustíveis líquidos. No entanto, o incremento em investimento na produção de biocombustíveis líquidos pode estar associado a diferentes dimensões do macroambiente. Decisões políticas, como a adição de biocombustíveis aos combustíveis fósseis; questões ambientais, 
como o aquecimento global e as metas do Protocolo de Kyoto; questões geopolíticas, como a concentração das reservas de petróleo em áreas de conflito ou questões econômicas como oferta e demanda, ilustram diferentes contextos por meio dos quais o macroambiente para os biocombustíveis pode ser configurado.

Levando-se em consideração que, primeiro, os agentes econômicos decidem seus investimentos a partir do planejamento estratégico das suas ações; segundo, o planejamento estratégico voltado ao incremento na produção de biocombustíveis líquidos deriva de uma etapa inicial de análise e interpretação do macroambiente; e, terceiro, o governo e a mídia são meios de expressão social que participam da configuração do macroambiente, pergunta-se: sob quais dimensões o governo e a mídia têm configurado o macroambiente para os biocombustíveis líquidos no Brasil ao longo do tempo? Existe semelhança na configuração do macroambiente feita pela mídia e pelo governo do Brasil?

Este artigo identifica as dimensões sob as quais o governo e a mídia do Brasil têm configurado o macroambiente para os biocombustíveis líquidos ao longo do tempo e testa a existência de similaridade entre o governo e a mídia na configuração do macroambiente. Para atingir tais objetivos, além da introdução, o artigo é composto por uma seção de revisão sobre a análise macroambiental, da área de planejamento estratégico e das relações entre mídia e governo. Na terceira seção são descritos o método e os procedimentos, seguida pelos resultados, que são discutidos na quarta seção. Por fim, na quinta seção, são apresentadas as conclusões.

\section{Planejamento estratégico: a análise do macroambiente}

Johnson, Scholes e Whittington (2005) identificam a presença de três núcleos básicos e necessários para que o processo de planejamento estratégico se complete: a posição estratégica, as escolhas estratégicas e a estratégia em ação. O núcleo responsável por definir a posição estratégica está interessado em avaliar os impactos do ambiente externo, dos recursos e competência da firma e das expectativas e competências dos grupos de interesse sobre a estratégia a ser adotada. Leidecker e Bruno (1984) usaram um modelo de sete passos para a elaboração da estratégia. Em ambos os estudos, a análise do ambiente é uma das primeiras etapas do planejamento estratégico.

Dill (1958) foi um dos primeiros autores a se preocupar com essa temática. Em seu estudo, o autor já afirmava que as influências das restrições 
impostas pelo ambiente eram essenciais para a ciência da gestão, uma vez que o comportamento das firmas depende dos padrões ambientais que servem à determinada firma e de como eles são interpretados e transformados em ações pelos gestores. No mesmo sentido, Terry (1977) afirma que o ambiente é o determinante primordial da forma e do comportamento de uma organização.

Mas o que é o ambiente? Qual o conceito? Quais as variáveis que o compõem? Uma definição amplamente aceita na literatura é a proposta por Thomas (1974), para quem, no campo da gestão, o termo ambiente deve ser entendido como aquele usado pela teoria geral dos sistemas, especialmente, dos sistemas abertos. De acordo com o autor, os sistemas abertos atribuem grande importância à ideia de que nas organizações, existindo em um ambiente dinâmico, seus recursos são amplamente afetados pelas forças desse ambiente.

Quanto às variáveis que compõem um determinado ambiente, é necessário identificar qual nível de ambiente se está analisando. Thomas (1974) propõe três níveis distintos de ambientes: ambiente geral, ambiente operacional e ambiente interno. Ou seja, o ambiente de uma firma é composto por camadas que vão do geral ao específico. $\mathrm{O}$ ambiente geral é composto pelas condições sociais, políticas, reguladoras, econômicas e tecnológicas existentes em um contexto nacional ou global. Leidecker e Bruno (1984) denominam esses diferentes níveis como: macroambiente, indústria e firma, sem mudar, no entanto, a concepção fundamental de análise.

Com o objetivo de utilizar a análise macroambiental para o planejamento estratégico, as variáveis encontradas nessa camada do ambiente são normalmente agrupadas em fatores ou dimensões. Quando se trata de definir quais são essas dimensões ou fatores que compõem o macroambiente, alguns autores utilizam dimensões adicionais ou complementares àquelas originalmente propostas por Thomas (1974). Uma síntese de estudos e das dimensões macroambientais utilizadas pelos autores pode ser visualizada no quadro.

Como conclusão sobre as dimensões que compõem o macroambiente de uma indústria, se pode dizer que inexiste um padrão único a ser seguido. A variedade e a quantidade de dimensões parecem também depender da área de atuação de determinada indústria. Contudo, se verifica que algumas dimensões são recorrentes entre os autores consultados e, de modo geral, as dimensões representadas pelo acrônimo Pestel parecem representativas de um macroambiente padrão. 


\section{As diversas dimensões do macroambiente, segundo diferentes autores}

\begin{tabular}{|c|c|}
\hline Autor & Dimensões do macroambiente \\
\hline Thomas (1974) & Social, política, reguladora, econômica e tecnológica \\
\hline Fahey e King (1977) & $\begin{array}{l}\text { Econômica, política, reguladora, social, cultural, tecnológica, } \\
\text { energética, mercadológica/industrial e financeira }\end{array}$ \\
\hline Preble, Rau e Reichel (1988) & Legal, econômica, política, competitiva, tecnológica e cultural \\
\hline Ginter e Duncan (1990) & Social, econômica, tecnológica e política/reguladora \\
\hline Ginter, Duncan e Capper (1991) & Econômica, política, social, tecnológica e regional \\
\hline Ginter et al. (1992) & Legal, econômica, política, competitiva, tecnológica e cultural \\
\hline Costa (1995) & Política, econômica, social e tecnológica - Pest \\
\hline Leonidou (1997) & $\begin{array}{l}\text { Física, demográfica, sociocultural, econômica, política/legal e } \\
\text { tecnológica }\end{array}$ \\
\hline Ngamkroeckjoti e Johri (2000) & $\begin{array}{l}\text { Econômica, sociocultural, política, ecológica e tecnológica } \\
\text { social, política, reguladora, tecnológica e econômica }\end{array}$ \\
\hline Fleisher e Bensoussan (2002) & Social, tecnológica, econômica, ecológica e política ou legal - Steep \\
\hline $\begin{array}{l}\text { Walsh (2005); Johnson, Scholes e } \\
\text { Whittington (2005) }\end{array}$ & $\begin{array}{l}\text { Política, econômica, sociocultural, tecnológica, ambiental } \\
\text { (environmental) e legal - Pestel }\end{array}$ \\
\hline Boiral (2006) & Econômica, política/reguladora, social e científica/tecnológica \\
\hline
\end{tabular}

Fonte: Elaborado pelos autores a partir da literatura consultada.

Definidos os conceitos e as dimensões que compõem o macroambiente no qual as firmas estão inseridas, convém entender como é realizado o processo de investigação do macroambiente para a elaboração do planejamento estratégico. Ginter e Duncan (1990) e Ginter, Duncan e Capper (1992) afirmam que o processo de análise macroambiental consiste de quatro atividades inter-relacionadas: ${ }^{1}$

v escaneamento - escanear o macroambiente significa investigar os sinais de perigo e possíveis mudanças que possam afetar os negócios da indústria;

\footnotetext{
${ }^{1}$ Os termos originais em inglês são: scanning, monitoring, forecasting and assessing. Embora o termo scanning possa ser traduzido como exploração ou investigação, optou-se por traduzi-lo como escaneamento por duas razões: evitar confusão com o sentido de exploração ambiental como o uso dos recursos disponíveis no ambiente; e, escaneamento, no sentido aqui empregado, é o processo de estudar detalhadamente o ambiente.
} 
v monitoração - a atividade de monitorar o macroambiente está associada ao processo de rastreamento das questões identificadas no processo de investigação;

- previsão - é o processo de estimar projeções de direções, escopo, velocidade e intensidade da mudança ambiental de forma plausível;

- avaliação - processo de avaliar o significado das tendências projetadas para a organização em termos do seu relacionamento com o ambiente externo.

Esses passos também estão presentes no modelo de planejamento estratégico proposto por Bates (1985). ${ }^{2} \mathrm{O}$ autor destaca três passos fundamentais para o processo de monitoração - o exame cuidadoso do ambiente é um deles. Com base nos modelos de análise do macroambiente descritos por Ginter e Duncan (1990), e Ginter, Duncan e Capper (1992), pode-se afirmar que o processo de escaneamento é um dos principais elementos do planejamento estratégico e é um dos primeiros passos a serem dados nessa direção. De acordo com o enfoque deste artigo, especial atenção deve ser dada ao processo de escaneamento do macroambiente. Logo, é importante entender de que maneira as firmas realizam essa etapa do planejamento estratégico: que tipos de informações são normalmente acessados? Quais as fontes de informação? Como essas informações são processadas?

Apesar da importância dessa etapa para um planejamento estratégico eficaz, a primeira constatação é que existem diferentes níveis de emprego das técnicas de escaneamento pelas firmas e a intensidade de seu uso por uma mesma firma pode variar ao longo do tempo (Fahey e King, 1977; Fahey, King e Narayanan, 1981; Stubbart, 1982). Contudo, em um ambiente marcado pela velocidade e intensidade das mudanças, é altamente recomendável o uso do escaneamento macroambiental para dar suporte às decisões estratégicas das firmas. Em Costa (1995) estão destacadas algumas razões pelas quais o uso de um processo sistematizado de análise externa à organização é relevante. Em sua essência, o escaneamento é um processo baseado na busca e tratamento de informações sobre um determinado macroambiente. Costa (1995) define o sistema de escaneamento estratégico de informações como um processo composto por seis passos e algumas tarefas associadas a cada um deles.

Ginter, Duncan e Capper (1992) ilustram com clareza como o processo de escaneamento do macroambiente captura e trata as informações. Por

\footnotetext{
${ }^{2} \mathrm{O}$ autor define o modelo como MAPing, dos termos: monitor, analyze e predict, em inglês.
} 
meio da figura 1, pode-se observar que, antes do escaneamento, as diversas informações sobre o macroambiente geral e o ambiente específico do setor analisado pelos autores encontram-se dispersas. Embora as informações estejam disponíveis, a identificação de algum padrão é uma tarefa difícil. Após o escaneamento, o resultado é um conjunto de informações categorizadas, organizadas, acumuladas e avaliadas. Pela ilustração, pode-se entender o escaneamento como um filtro ordenador do conjunto de informações acessadas pela firma ou indústria, pois após sua aplicação os padrões macroambientais podem ser identificados e avaliados.

\section{Figura 1}

Tratamento das informações através do processo de escaneamento

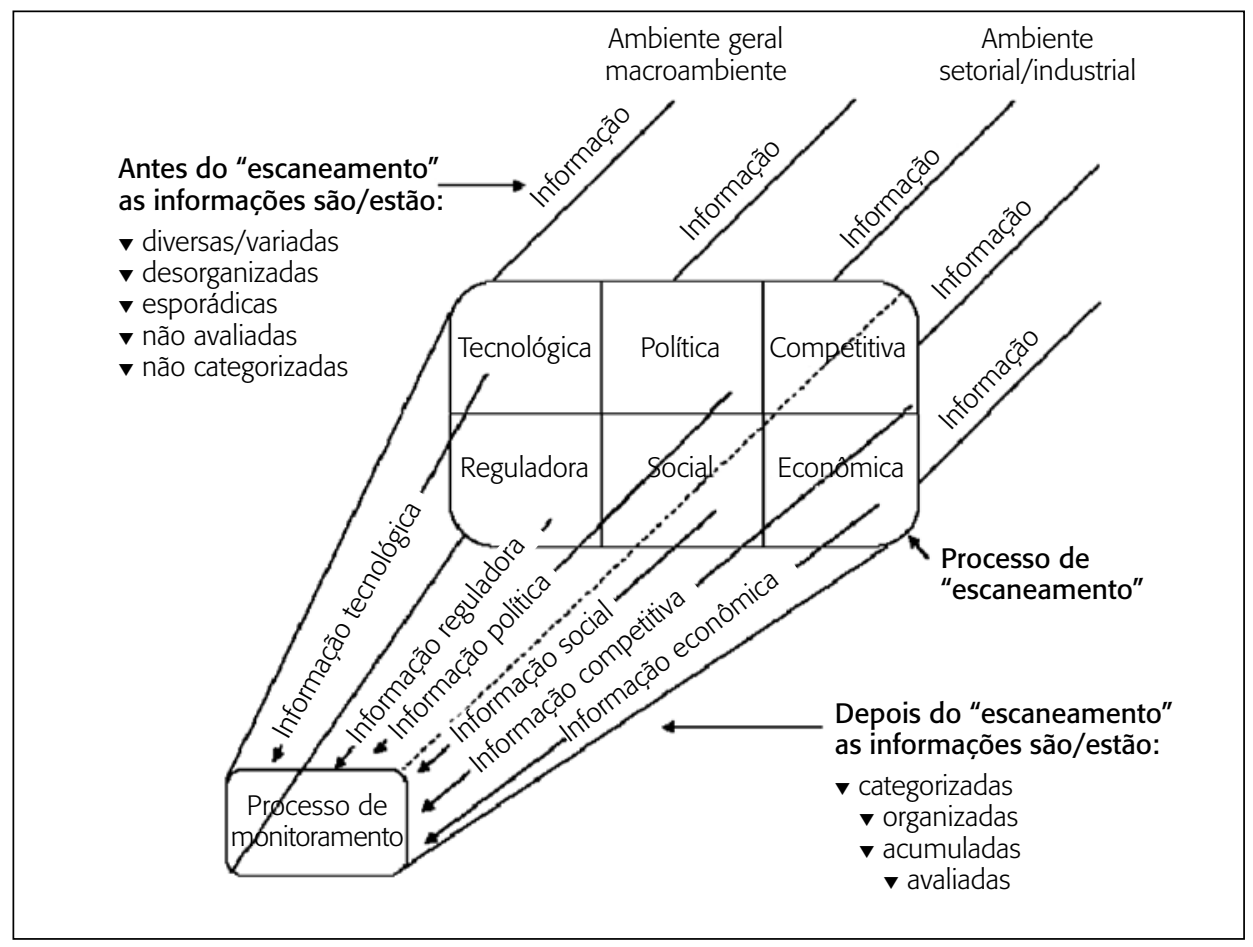

Fonte: Ginter, Duncan e Capper (1992:255).

A figura 1 mostra que, de fato, as informações são a matéria-prima para o processo de escaneamento do macroambiente e que irá resultar no planejamento estratégico. Então, quais as fontes de informações utilizadas para essa finalidade? Analisando diferentes estudos na área, foi possível identificar a 
presença de dois grandes grupos: fontes internas e fontes externas (pessoais e impessoais). Os exemplos de fontes de informação para cada um desses grupos podem ser visualizados na figura 2 .

Estudos mais recentes no campo do escaneamento do macroambiente têm chamado atenção para a importância da rede mundial de computadores como fonte de informação. A internet promoveu um significativo acréscimo no volume de informações disponíveis para a tomada de decisão. Auster e Choo (1993, 1994); Choo (1994, 1999); Liu (1998); Choo, Detlor e Turnbull (2000); Liu, Turban e Lee (2000); e Decker, Wagner e Scholz (2005) são alguns dos autores de estudos desenvolvidos nos últimos anos chamando atenção para a importância das fontes eletrônicas de informações para os executivos.

Figura 2

\section{Classificação e tipos de fontes de informação}

\begin{tabular}{|lll|} 
& Fontes de informação & \\
Colegas & Advogados & Agências do governo \\
Executivos & Associados & Conferências \\
corporativos & Banqueiros & Estudos externos \\
Executivos das & Competidores & Internet \\
divisões internacionais & Conferências & Jornais \\
Executivos de & Consultores & Organizações \\
produtos & Consumidores & públicas \\
Executivos dos & Contadores do & Publicações de \\
escritórios centrais & instituições regionais \\
internacionais & setor público & Publicações de \\
Executivos e seus & Distribuidores & negócios \\
pares & Encontros fortuitos & Publicações do \\
Executivos em outros & Eventos ocasionais & governo \\
países & Exposições & Publicações dos \\
Funcionários locais & Convenções & competidores \\
Gerentes & Fornecedores & Rádio \\
Pessoal de apoio & Membros do & Relatórios externos \\
Subordinados & governo & Relatórios \\
Superiores & Relacionamentos & Revistas de negócios \\
Supervisores & sólidos (guanxi) & Televisão \\
& Seminários & \\
\hline
\end{tabular}

Fonte: Elaborado pelos autores a partir dos estudos de Keegan (1974); Ginter e Duncan (1990); Ngamkroeckjoti e Johri (2000); e Jogaratnam e Law (2006). 
Se de um lado o acesso às informações foi facilitado, de outro lado existe a dificuldade de analisar um volume tão grande de dados e informações de forma a extrair os elementos fundamentais para o planejamento das atividades das organizações. A solução para esse problema parece vir da junção entre: a teoria e o conceito de escaneamento do macroambiente; e as novas tecnologias de informação (TIs) desenvolvidas para o tratamento de dados eletrônicos, para extrair um conjunto reduzido e estruturado de informações. Os estudos de Liu (1998), Myers (1999), Wei e Lee (2004), Decker, Wagner e Scholz (2005), Aasheim e Koheler (2006) e de Camponovo (2006) são exemplos de que o escaneamento eletrônico das dimensões macroambientais tende a ser uma poderosa ferramenta para o ambiente global atual, em que as informações são muitas e digitalizadas.

No conjunto de novas técnicas e tecnologias para o escaneamento macroambiental, o uso da mineração em textos (text mining) vem sendo discutido e apresentado como uma das técnicas inteligentes para o tratamento de um grande volume de informações. Em seu livro sobre essa temática, Halliman (2001) discute com profundidade uma aplicação prática do uso da mineração de dados, tanto para determinar as forças macroambientais, quanto para a análise de cenários, que é uma etapa posterior no processo de planejamento estratégico. Ferneda, Prado e Silva (2003) e Lau, Lee e Ho (2005) também utilizaram a mineração de textos como ferramenta de análise para a identificação das dimensões macroambientais associadas ao ambiente de negócios das indústrias de comunicação e hotelaria.

\section{Aspectos da relação entre governo e mídia}

Embora a maioria dos estudos sobre as relações entre mídia e governo analise essa relação a partir dos aspectos eleitorais associados à mídia, no contexto deste artigo o ator governo é mais amplo, envolvendo principalmente a elaboração de políticas e programas públicos. Já a mídia de comunicação de massa pode ser analisada a partir de quatro componentes principais: jornais, televisão, rádio e revistas (Chaffee e Frank, 1996), embora aqui o foco tenha sido a mídia escrita (jornais).

Diversos estudos têm mostrado que as relações entre governo e mídia são bidirecionais, ou seja, ambos estão sujeitos a influenciar e ser influenciados. As razões para aceitar que o governo tem influência nas notícias que são veiculadas pela mídia podem ser tomadas, por exemplo, da afirmação de Gamson e Modigliani (1989) sobre o papel do governo como 
patrocinador de enquadramentos. Por outro lado, a mídia pode influenciar as decisões do governo. Strömberg (2001) cita três formas pelas quais tal influência pode ocorrer:

v influenciando a competição eleitoral;

v informando o que está sendo feito e que nem sempre é facilmente percebido;

v influenciando as decisões ao atribuir maior peso a certas questões.

Além disso, Strömberg (2004) afirma que ao priorizar as notícias de certos grupos de interesse, como contribuintes e interesses do consumidor, o viés da mídia pode alterar a competição política e introduzir esse viés nas políticas públicas.

Em outras situações, as influências entre governo e mídia fecham um ciclo. Ao analisar a intervenção dos Estados Unidos na Somália no final da década de 1980, início da década de 1990, Mermin (1997) buscou identificar se a política internacional do governo norte-americano havia sido influenciada pela mídia daquele país. $\mathrm{O}$ autor partiu de duas suposições de como a Somália passou a ser notícia na mídia norte-americana: primeira, pela ação independente dos jornalistas; e, segunda, ação de jornalistas influenciados por setores do governo. A conclusão do autor é de que houve influência do governo sobre a mídia e que as notícias veiculadas sobre o assunto acabaram dando suporte à política internacional adotada pelo governo.

Duas afirmações feitas por Mermin (1997) são conclusivas sobre as relações entre governo e mídia. A primeira é que, se a mídia consegue direcionar a atenção do governo para algumas questões, ela também pode influenciar na tomada de decisão relacionada às políticas públicas definidas pelo governo. A segunda é que, assim como a mídia tem poder de mover o governo em alguma direção, este também tem o poder de influenciar a direção da mídia. Nessa discussão fica clara a distinção de Van Gorp (2007) sobre os enquadramentos pela mídia e os enquadramentos através da mídia.

Alguns estudos, porém, identificam diferenças na forma como os vários recursos de mídia transmitem as informações sobre o governo. Becker e Whitney (1980), por exemplo, identificaram que a televisão transmite uma imagem mais negativa do governo quando comparada aos jornais. Hollander (1997) concluiu também que a televisão é menos eficiente na transmissão e disseminação do conhecimento sobre as políticas públicas e o governo. Chaffee e Frank (1996) identificaram que a televisão destina mais tempo às informações sobre os candidatos (em campanhas eleitorais), enquanto os jornais dão mais destaque aos partidos políticos. A televisão é mais utilizada pelo 
público jovem, por imigrantes e cidadãos com menor nível de interesse em questões políticas. Já os jornais são mais utilizados por aquelas pessoas que estão ativamente em busca de informações. Os autores concluíram, também, que os jornais fazem coberturas mais amplas, buscando eliminar diferenças entre os distintos estratos da população, e que a rádio e as revistas são meios menos efetivos que a televisão e o jornal.

\section{Método e procedimentos}

O método utilizado neste artigo foi a análise documental a partir das notícias veiculadas pela mídia escrita do Brasil e de documentos oficiais do governo brasileiro. Karanikas e Theodoulidis (2002); e Hale (2005) afirmam que 80\% das informações estão presentes em diversos tipos de documentos escritos. Para transformar tais informações em conhecimento gerenciável foram utilizados o conceito de descoberta de conhecimento em textos e a técnica de mineração em textos ${ }^{3}$ (Halliman, 2001). Os procedimentos adotados para a mineração em textos seguiram uma estrutura híbrida, a partir dos estudos de Liddy (2000); Karanikas e Theodoulidis (2002); El Wakil (2002); Silva e colaboradores (2004); e Hippner e Rentzmann (2006).

A seleção das notícias veiculadas pela mídia e dos documentos governamentais foi realizada a partir de uma lista de palavras-chave, representativas do objeto de pesquisa "biocombustíveis líquidos", dada a frequência com que têm ocorrido na literatura tratando de questões relativas à bioenergia, à bioeconomia (bioeconomy) e aos biocombustíveis. As palavras-chave selecionadas foram: biocombustível, biocombustíveis, etanol, álcool, biofuel, biofuels, biofuel, bio-fuels, biodiesel e bio-diesel. Os documentos nos quais a palavra-chave álcool estava relacionada à bebida alcoólica foram descartados. A partir do conjunto de palavras-chave, foram realizadas pesquisas de busca nos arquivos eletrônicos dos jornais: Folha de S.Paulo e Valor Econômico, por serem jornais de ampla circulação em território nacional. Os documentos governamentais foram pesquisados em diversas páginas do governo brasileiro disponíveis na rede mundial de computadores. Foram acessadas páginas de todos os ministérios, secretarias federais e autarquias e, utilizando as ferramentas de busca disponíveis nas próprias páginas, foram pesquisados os documentos contendo as palavras-chave relacionadas aos biocombustíveis líquidos. Importante des-

\footnotetext{
${ }^{3}$ Tradução dos conceitos knowledge discovery in text (KDT) e text mining (TM).
} 
tacar que foram excluídas da coleta de documentos governamentais as informações disponíveis na "sala de imprensa" dos diversos órgãos acessados.

A busca e a coleta dos documentos da mídia e do governo e a construção da base de dados preliminar tiveram início na primeira semana de fevereiro de 2007 e foram concluídas na última de junho de 2007. Buscou-se cobrir um período de 10 anos, para tanto foram coletados os documentos, em formato eletrônico, relativos aos anos de 1997 até 2006, que foram armazenados em duas bases distintas de dados. Ao final desse processo, foram coletados 4.121 documentos da mídia brasileira e 673 documentos oficiais do governo brasileiro.

$\mathrm{Na}$ etapa seguinte, os conteúdos dos documentos foram transferidos para uma base de dados construída com auxílio do software QDA Miner ${ }^{\circledR}$, preparando os documentos para posterior aplicação do processo de mineração. Como o software QDA Miner ${ }^{\circledR}$ utiliza textos em formato *RTF (rich text format) para a construção das bases de dados, 49 documentos do governo foram perdidos por estarem com os conteúdos bloqueados. Logo, a composição final da base de dados foi de 4.121 documentos da mídia e 624 documentos governamentais.

Para ter conhecimento dos textos, foi necessário construir uma estrutura analítica capaz de extrair as informações relevantes, uma vez que inexiste uma metodologia única e específica para isso. O uso de uma lista de palavras-chave é frequentemente utilizado, como pode ser visto em Vincent (2006), Crawley (2007) e Singh, Hu e Roehl (2007). O primeiro passo para construir uma estrutura específica esteve relacionado à definição das dimensões macroambientais a serem utilizadas. De acordo com a literatura sobre análise do macroambiente, as dimensões mais frequentemente utilizadas são aquelas relativas ao acrônimo "pestel", ou seja, política, econômica, sociocultural, tecnológica, ambiental (environmental) e legal (Walsh, 2005; Johnson, Scholes e Whittington, 2005). O número de dimensões e a denominação das mesmas variam de um estudo para outro, dependendo do interesse específico do estudo, do ambiente estudado e/ou da atividade, possibilitando certa flexibilidade. Para este artigo foram utilizadas nove dimensões: agronômica, ambiental, cultural, econômica, geopolítica, legal, política, social e tecnológica.

Definidas as dimensões macroambientais, os passos seguintes buscaram identificar as palavras-chave representativas de cada dimensão, que serão tratadas aqui como "palavras-dimensão" ou palavras-d, que são os termos relevantes que melhor discriminam uma determinada dimensão macroambiental. Assim, nove diferentes listas de palavras-d foram definidas. O conjunto de palavras-d para cada dimensão foi definido a partir dos índices TF*IDF de relevância das palavras dentro dos documentos científicos publicados em 
periódicos das áreas de conhecimentos afins às dimensões macroambientais (Aizawa, 2003; Jing, Huang e Shi, 2002). A quantidade de "palavras-d" sob cada dimensão foi definida através das medidas de percentis, selecionando-se a quantidade de palavras-d que melhor discriminaram cada dimensão. Em média, foram utilizadas 14 palavras-d para cada dimensão. Como algumas palavras-d foram comuns a duas ou mais dimensões, foram adicionadas regras à estrutura de análise e extração do conhecimento. As regras levam em conta a ocorrência conjunta de termos em um mesmo documento. Para a definição das regras foi utilizado o coeficiente de Jaccard (Chung e Lee, 2001).

A mineração em textos foi realizada utilizando-se as bases de documentos textuais em formato eletrônico e a estrutura de análise e extração de conhecimento construída a partir das dimensões macroambientais e suas respectivas palavras-d. Utilizando o módulo WordStat do software SIMStat ${ }^{\circledR}$, foi possível contabilizar a frequência com que cada palavra-d ocorreu em cada conjunto de documentos e, consequentemente, a frequência com a qual o enquadramento dos biocombustíveis líquidos pela mídia e pelo governo do Brasil ocorreu sob cada uma das dimensões macroambientais.

Para a análise dos resultados, foram utilizadas as frequências absolutas e relativas da ocorrência dos enquadramentos sob cada uma das dimensões macroambientais. A partir das frequências, foram construídos dendogramas, agrupando as dimensões com maiores coeficientes de similaridade de Jaccard para analisar a ocorrência conjunta das dimensões nos documentos da mídia e do governo. Também foram construídos heatmaps a partir da frequência de cada dimensão em relação ao conjunto total de palavras presentes nos documentos. Por fim, foram realizados testes de aderência e de homogeneidade para testar as semelhanças e/ou diferenças no uso das dimensões macroambientais pela mídia e pelo governo para a configuração do macroambiente para os biocombustíveis líquidos.

\section{Resultados}

Nesta seção são apresentados os principais resultados obtidos na mineração em textos realizada nos documentos da mídia e do governo, analisando-se os resultados de forma individual num primeiro momento e, posteriormente, fazendo-se a análise comparativa entre ambos os meios de expressão social.

Os resultados das frequências relativas dos enquadramentos sob cada uma das dimensões macroambientais pela mídia podem ser observados na figura 3. Os resultados indicam pelo menos quatro características interessan- 
tes: primeira, uma elevada importância relativa da dimensão econômica nos primeiros períodos. Entre 2001 e 2006 a importância dessa dimensão reduziu sensivelmente, apresentando uma tendência decrescente desde então; segunda, a crescente importância da dimensão tecnológica ao longo do período analisado, sendo a dimensão de maior frequência relativa nos últimos dois períodos quando as discussões sobre os biocombustíveis líquidos foram mais intensas na mídia brasileira; terceira, a importância relativa decrescente da dimensão política ao longo do período, especialmente após o ano 2000; quarta, a tendência de aumento na importância relativa da dimensão geopolítica (especialmente após 2001), chegando a ser a terceira dimensão mais importante nos últimos três anos da série estudada, e da dimensão agronômica.

Tais comportamentos na importância relativa de cada dimensão macroambiental indicam que o enquadramento dos biocombustíveis líquidos pela mídia mudou nos últimos 10 anos. Entre 1997 e 2000, pode-se dizer que o macroambiente foi configurado sob as dimensões: econômica e política, sendo que os biocombustíveis líquidos (especialmente o álcool) eram tratados de forma similar a outros bens econômicos de consumo normalmente incorporados à cesta de produtos dos consumidores brasileiros, onde aspectos como preços, oferta e demanda estavam na pauta das discussões. A partir de 2001, parece ter havido uma mudança significativa na configuração do macroambiente para os biocombustíveis. Com a inclusão de outras fontes de biocombustíveis, como o biodiesel, e a crescente discussão a respeito do uso de biocombustíveis mundialmente, as dimensões tecnológica e geopolítica aumentaram suas participações relativas na configuração do macroambiente. Possivelmente, discussões no sentido de desenvolver novas tecnologias para a produção de biocombustíveis baseados na agricultura formaram a base das discussões tecnológicas. Enquanto aspectos relacionados às políticas dos diferentes países quanto ao uso dos biocombustíveis em escala global, como forma de manter o desenvolvimento econômico mundial, parece ser uma interpretação razoável da dimensão geopolítica.

A interpretação tem como base as palavras-d que ocorreram com maior frequência nas referidas dimensões. Na dimensão econômica as palavras-d mais frequentes foram: preços, preço, economia, mercado, trabalho e imposto/tributo. As palavras-d: governo, estados, políticas, política, público e social foram as que apareceram mais na dimensão política. Sob a dimensão tecnológica, as palavras-d mais frequentes foram: produtos, empresas, projeto, mercado, tecnologia e desenvolvimento; enquanto as palavras-d mais usadas na dimensão geopolítica foram: estados, países, mundo, econômico(a), política e global. 
Figura 3

Frequência relativa das dimensões macroambientais sob as quais os biocombustíveis líquidos foram enquadrados pela mídia do Brasil no período de 10 anos

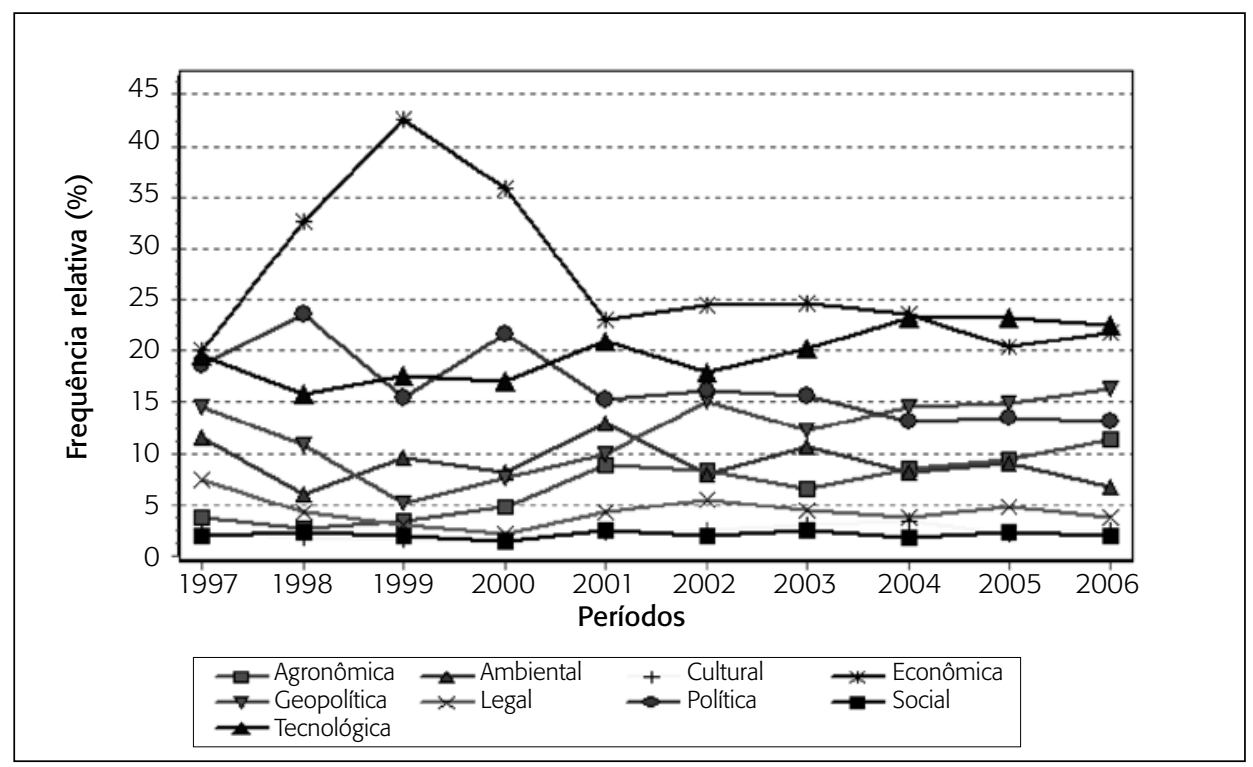

Fonte: Dados da pesquisa.

A participação relativa de cada dimensão na configuração do macroambiente para os biocombustíveis líquidos pelo governo pode ser visualizada na figura 4. Pelo menos duas características principais do comportamento da participação relativa das dimensões macroambientais podem ser destacadas. Primeira, a ampla diferença com que a dimensão tecnológica está presente nos documentos do governo em relação às demais dimensões. Embora apresente uma tendência decrescente ao longo do período estudado, em nenhum momento essa dimensão foi superada por outra. A segunda característica é o comportamento das demais dimensões. É difícil observar visualmente a presença de algum padrão de comportamento quanto à participação relativa das dimensões macroambientais. Ao longo do período ocorrem diversas alterações na ordem de importância das dimensões. Aplicando-se uma linha de tendência às linhas de frequência das dimensões, percebe-se uma tendência de leve crescimento nas dimensões agronômica, geopolítica e ambiental, e tendência de leve redução na frequência relativa das dimensões econômica, legal e política. Com exceção da dimensão tecnológica, o governo brasileiro parece explorar, 
de forma relativamente constante, todas as dimensões macroambientais na configuração do macroambiente para os biocombustíveis líquidos. Ou seja, o enquadramento dos biocombustíveis líquidos pelo governo parece ter levado em conta aspectos relativos a todas as dimensões do macroambiente de forma relativamente equilibrada, excluindo-se as questões tecnológicas que predominaram no período.

Figura 4

Frequência relativa das dimensões macroambientais sob as quais os biocombustíveis líquidos foram enquadrados pelo governo do Brasil no período de 10 anos

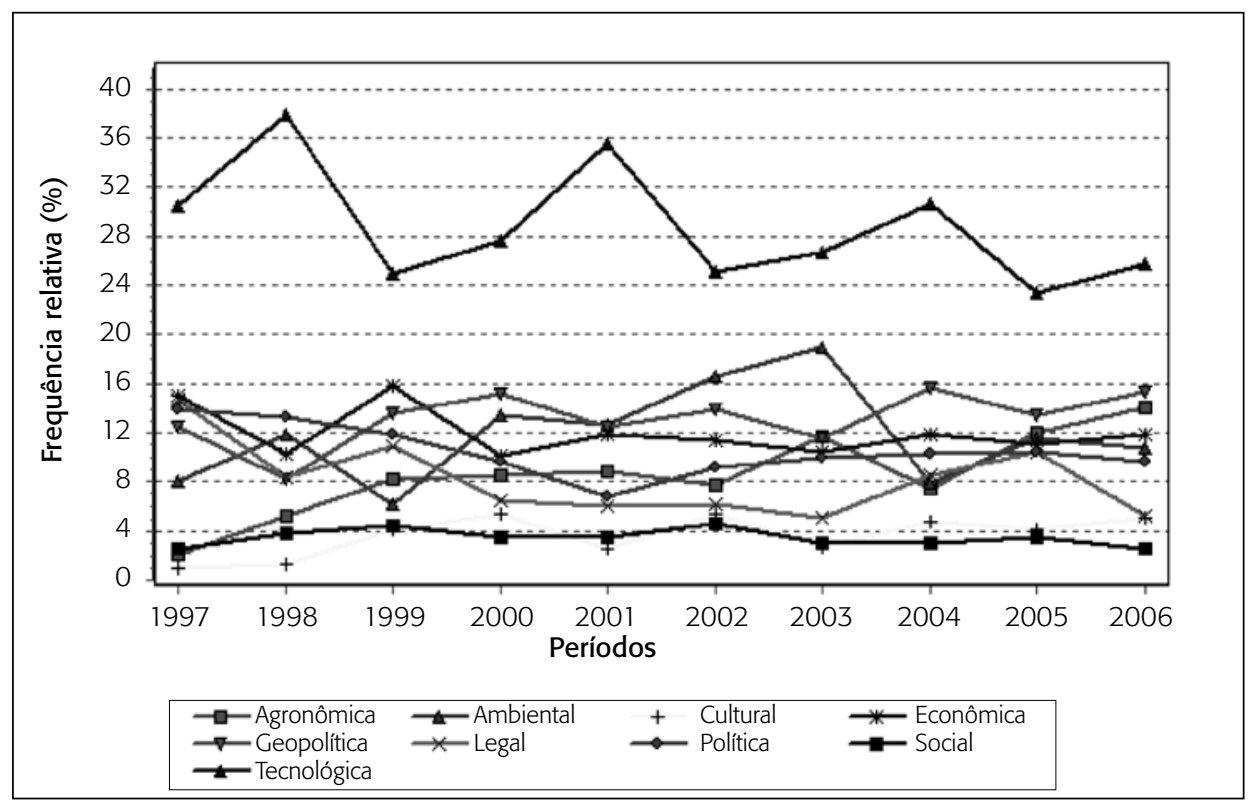

Fonte: Dados da pesquisa.

Dois eventos relacionados ao governo brasileiro que poderiam ter impactado a importância relativa da dimensão social foram: primeiro, a eleição de Luiz Inácio Lula da Silva como presidente do Brasil e sua posse no início de 2003. Por ser um presidente cuja trajetória política esteve ligada a movimentos sociais, poderia se esperar que houvesse algum reflexo das ações governamentais relacionadas aos biocombustíveis líquidos sobre a importância relativa da dimensão social; segundo, o lançamento do Plano Nacional de Agroenergia, em 2005, do qual poderiam ter sido derivados documentos cujo enquadra- 
mento dos biocombustíveis líquidos fosse feito sob a dimensão social, uma vez que havia pontos do plano com claro enfoque em programas sociais, em especial os relacionados à reforma agrária. No entanto, os resultados indicam a inexistência de alterações significativas na importância relativa da dimensão social nos períodos posteriores a estes eventos. $\mathrm{E}$ a importância relativa dessa dimensão em períodos posteriores foi menor do que em períodos anteriores à posse do presidente Lula. Tais resultados indicam que: na configuração do macroambiente para a produção de biocombustíveis líquidos pelo governo brasileiro, a dimensão social está ausente entre as mais importantes. Pelo contrário, nos períodos pós-posse do presidente Lula a dimensão social foi a de menor importância relativa; ou a estrutura analítica utilizada na presente pesquisa foi ineficaz em captar o enquadramento social dos biocombustíveis líquidos nos documentos do governo.

Embora um padrão melhor definido de enquadramento dos biocombustíveis líquidos pelo governo pareça estar ausente nos documentos coletados, identificar as palavras-d mais frequentes em cada dimensão pode indicar a direção da configuração do macroambiente. As palavras-d que ocorreram com maior frequência sob a dimensão tecnológica foram: produção, desenvolvimento, produto, mercado e sistema. Sob a dimensão geopolítica foram as palavras-d: desenvolvimento, países, estado, econômica(o), políticas e sociais. As palavras-d mais frequentes da dimensão econômica foram: mercado, social, econômico(a), preços e política. As palavras-d: energia, processo, sistema, ambiental e ambiente são as que ocorrem com maior frequência sob a dimensão ambiental.

Analisando as frequências totais acumuladas das ocorrências dos enquadramentos sob cada uma das dimensões macroambientais na mídia e no governo, conforme ilustrado na figura 5, percebe-se a existência de semelhanças e diferenças na configuração do macroambiente pela mídia e pelo governo. As principais dimensões utilizadas pela mídia foram: econômica, tecnológica, política e geopolítica. Já no governo predominaram as dimensões: tecnológica, geopolítica, econômica, ambiental e agronômica, com amplo domínio da dimensão tecnológica. Em termos gerais, percebe-se algum nível de semelhança entre a mídia e o governo ao verificar que as dimensões econômica, tecnológica e geopolítica são comuns a ambos os meios de expressão social. No entanto, a principal diferença entre a mídia e o governo está na intensidade com a qual cada uma dessas dimensões se expressa na configuração do macroambiente para os biocombustíveis líquidos. Exemplificando, embora a dimensão econômica esteja entre as mais utilizadas, tanto pela mídia, quanto 
pelo governo, as referências a questões econômicas são mais frequentes na mídia do que no governo.

Figura 5

Frequência relativa das dimensões macroambientais sob as quais os biocombustíveis líquidos foram enquadrados pela mídia e pelo governo brasileiro - acumulado de 10 anos

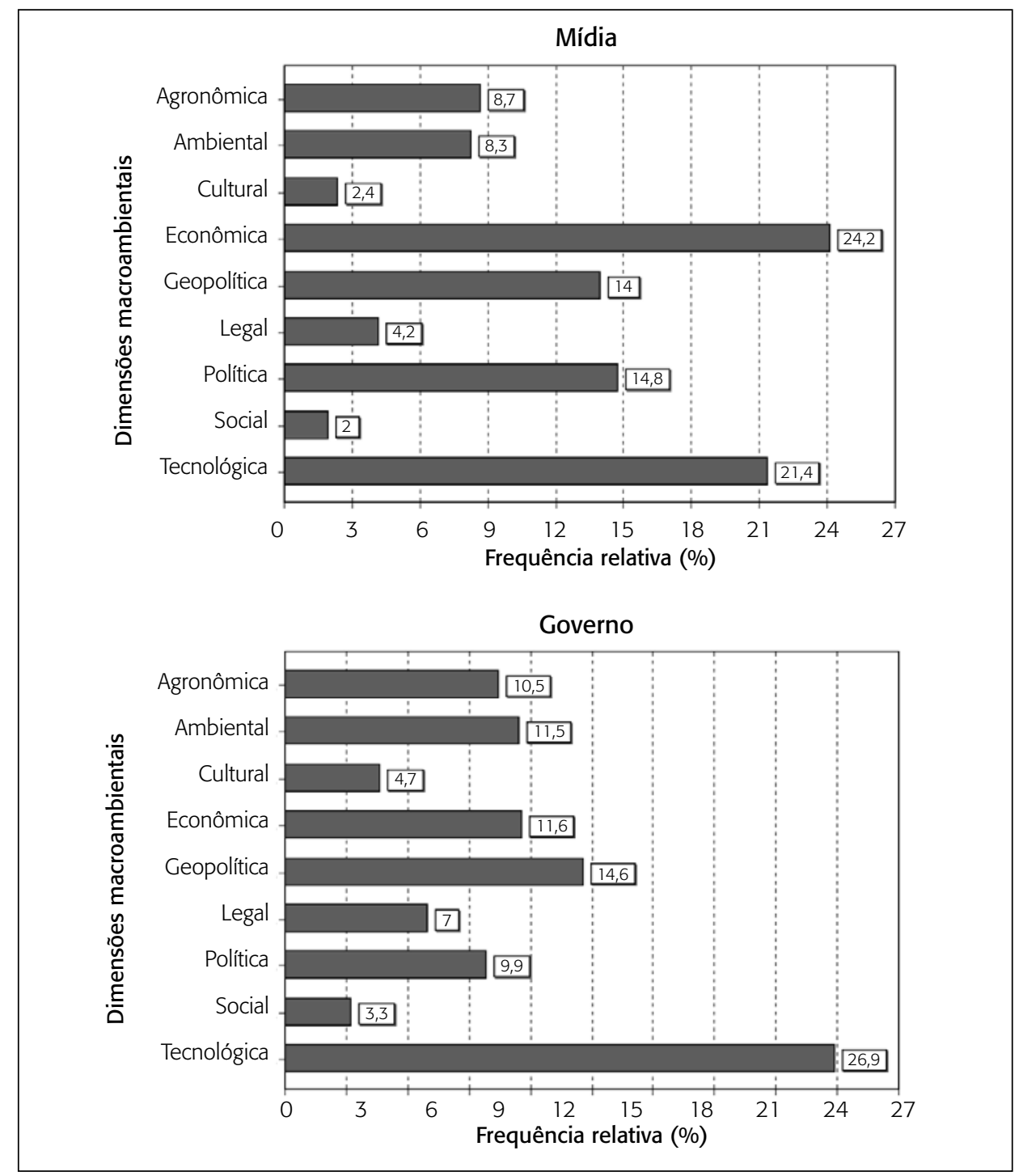

Fonte: Dados da pesquisa. 
Outro aspecto analisado foi o uso conjunto das dimensões macroambientais para configurar o macroambiente para os biocombustíveis líquidos pela mídia e pelo governo. Na figura 6 estão ilustrados os agrupamentos das principais dimensões utilizadas conjuntamente pela mídia e pelo governo para configurar o macroambiente para os biocombustíveis líquidos, a partir dos valores mais elevados do coeficiente de similaridade de Jaccard.

\section{Figura 6}

Dendograma do agrupamento das dimensões macroambientais para a mídia e o governo a partir do coeficiente de Jaccard

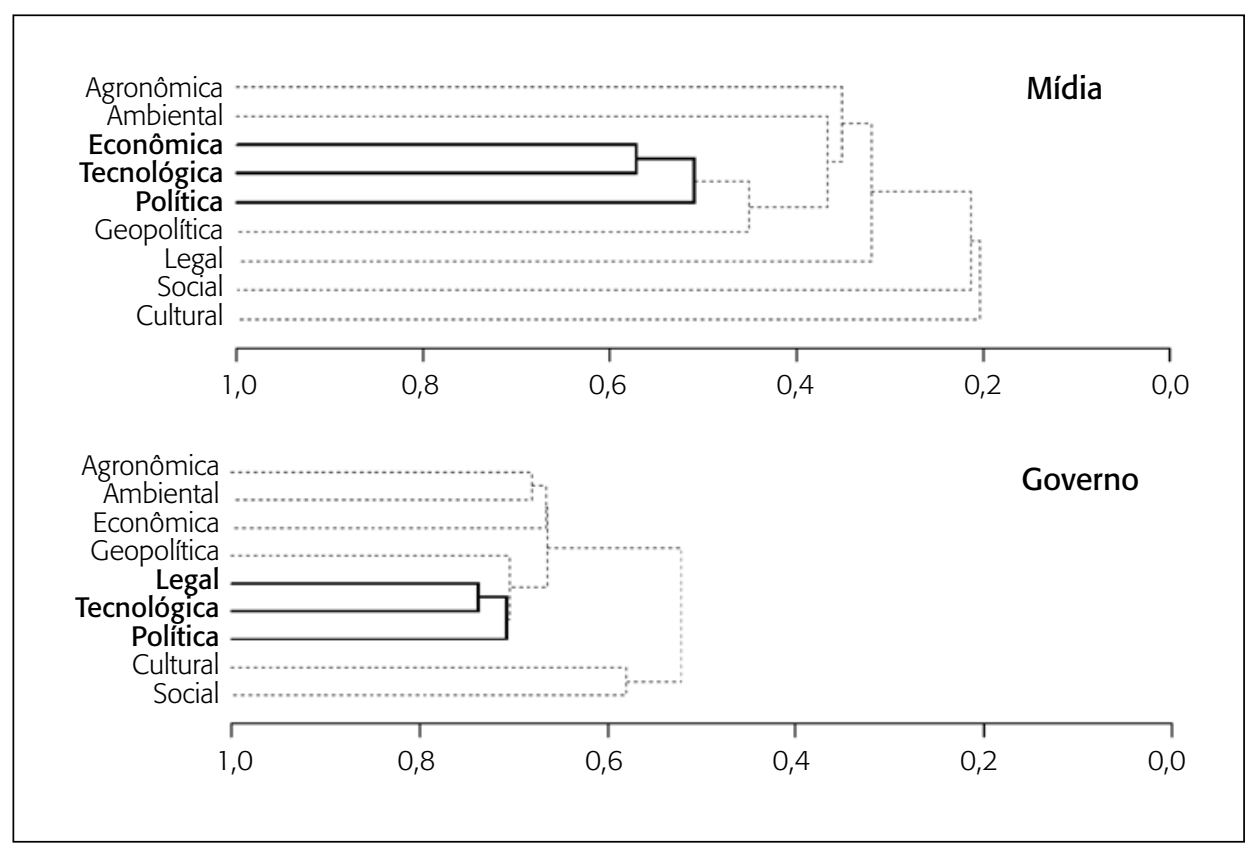

Fonte: dados da pesquisa.

Analisando a figura 6, observa-se a presença de alguma similaridade no uso conjunto das dimensões na configuração do macroambiente para os biocombustíveis pela mídia e pelo governo. Na mídia, a configuração macroambiental utiliza as dimensões [(econômica $\approx$ tecnológica) $\approx$ política], enquanto no governo a ordem de uso conjunto das dimensões é [(legal $\approx$ tecnológica) $\approx$ política]. Existe similaridade entre a mídia e o governo quanto ao uso conjunto das dimensões tecnológica e política para configurar o macroambiente. No entanto, enquanto a dimensão legal é mais saliente no governo, na mídia 
é a dimensão econômica que aparece com maior destaque. Tal resultado pode ser explicado pela natureza distinta dos meios de expressão social. Enquanto a mídia tem a característica de expressar os assuntos do cotidiano socioeconômico da sociedade, ao governo cabe a função reguladora das atividades socioeconômicas.

Outra análise realizada foi da frequência da ocorrência de enquadramentos sob cada uma das dimensões macroambientais em relação ao total de palavras presentes nos documentos da mídia e do governo. Na figura 7 podem ser visualizadas essas frequências para cada um dos períodos analisados, comparando o desempenho da mídia e do governo pelos heatmaps.

Visualmente, podem ser observadas semelhanças e diferenças entre a mídia e o governo. Na mídia, os maiores valores observados ocorreram em 1999 e 2000 sob a dimensão econômica. Além disso, as dimensões econômica e política perderam importância relativa na configuração macroambiental nos últimos anos para as dimensões tecnológica e geopolítica, embora a dimensão econômica tenha sido a mais importante ao longo do período. No governo, por outro lado, percebe-se a forte predominância da dimensão tecnológica, que apresenta maior frequência relativa em todos os períodos analisados. Outro aspecto de destaque no governo é a baixa frequência com a qual as dimensões social e cultural têm ocorrido, mesmo nos períodos depois de 2003, após o início do governo Lula. O principal ponto de convergência entre a mídia e o governo é percebido na dimensão tecnológica, que passou a estar presente com maior freqência na mídia a partir de 2001, um ano após ela ter sido a mais frequente nos documentos do governo. Esse resultado pode indicar que a mídia está atuando na transferência das decisões do governo para sua audiência.

Para testar estatisticamente a presença de semelhança ou diferença no uso das dimensões para a configuração do macroambiente para os biocombustíveis líquidos pela mídia e pelo governo, foram realizados testes de aderência e homogeneidade. O resultado do teste de aderência pode ser observado na tabela 1. De acordo com os valores obtidos para a estatística de teste $\chi^{2}$ a partir da frequência total de cada dimensão, acumulada ao longo dos períodos analisados, percebe-se a inexistência de aderência entre a mídia e o governo, indicando que os dois meios de expressão diferem estatisticamente quanto às proporções sob as quais as dimensões são utilizadas. Cabe destacar que o resultado indica que em pelo menos uma das dimensões as proporções diferem estatisticamente na mídia e no governo. 
Figura 7

Heatmaps das frequências relativas das dimensões macroambientais na mídia e no governo em relação ao total de palavras presentes nos documentos, por período

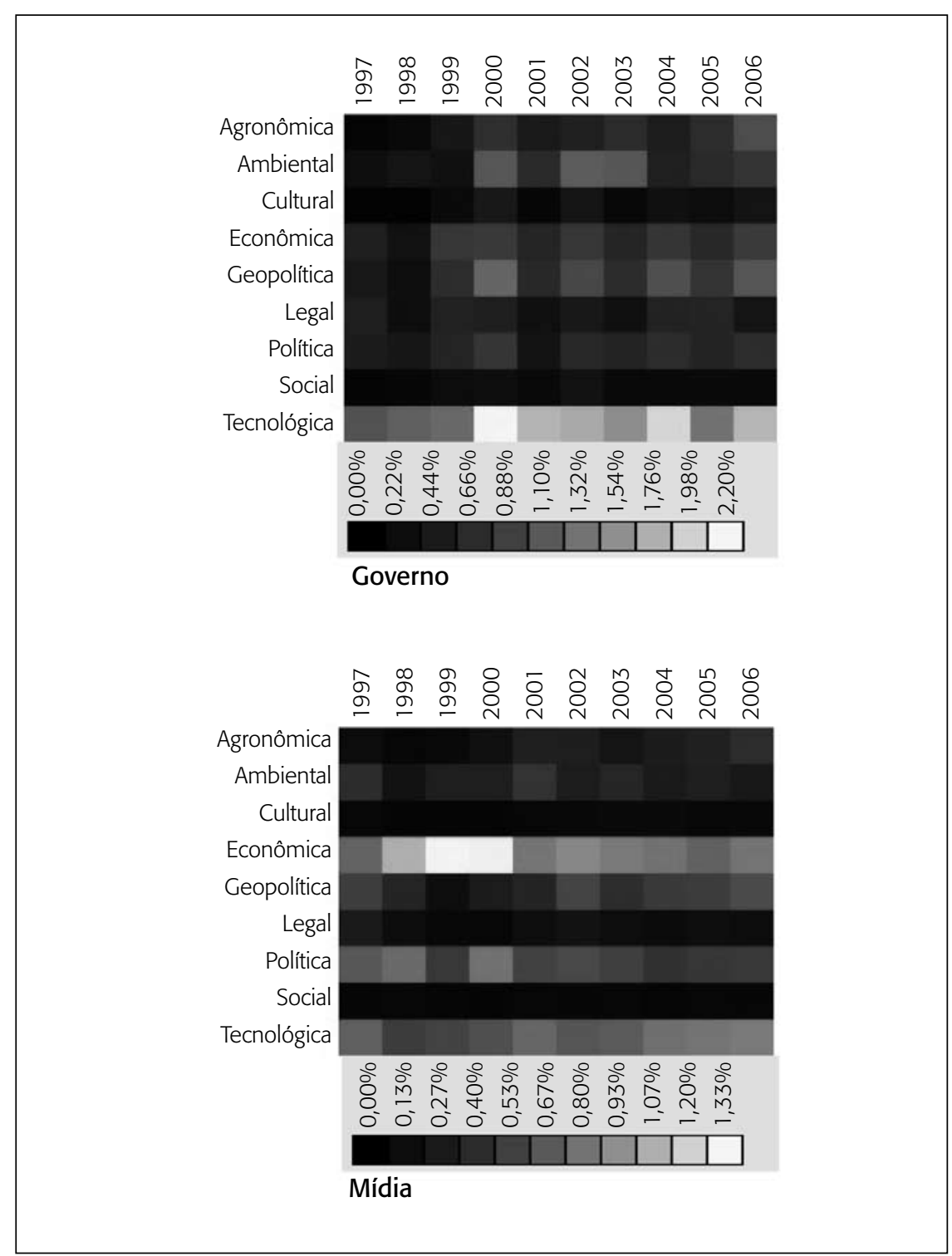

Fonte: Extraído dos dados da pesquisa. 
Tabela 1

Teste de aderência entre a mídia e o governo - total das dimensões

\begin{tabular}{|l|c|}
\hline Teste de aderência & Valor da estatística $\chi^{2}$ \\
\hline Governo em relação à mídia & 32611,9 \\
Mídia em relação ao governo & 11183,8 \\
\hline
\end{tabular}

$\mathrm{gl}=8 ; \alpha=0,01 ; \chi^{2}$ crítico = 20,090; *p $<0,01$

Os testes de homogeneidade foram realizados em três momentos: primeiro, utilizando as frequências acumuladas das dimensões macroambientais ao longo dos 10 anos (tabela 2); segundo, utilizando as frequências de cada dimensão em cada ano (tabela 3); e, terceiro, utilizando a frequência de cada dimensão em cada um dos anos, ou seja, analisando o comportamento da dimensão ao longo dos 10 anos (tabela 4).

Tabela 2

Teste de homogeneidade entre a mídia e o governo total das dimensões

\begin{tabular}{|c|c|}
\hline Teste de homogeneidade & Valor do $\chi^{2}$ \\
\hline Mídia $x$ governo & 7890,4 \\
\hline $\mathrm{g} \mid=8 ; \alpha=0,01 ; \chi^{2}$ crítico $=20,090 ; * \mathrm{p}<0,01$ &
\end{tabular}

Tabela 3

Teste de homogeneidade entre a mídia e o governo - por período

\begin{tabular}{|cc|}
\hline Períodos & Valor da estatística $\chi^{2}$ \\
\hline 1997 & 100,9 \\
1998 & 490,2 \\
1999 & 1312,1 \\
2000 & 2313,5 \\
2001 & 305,5 \\
2002 & 808,9 \\
2003 & 588,8 \\
2004 & 921,7 \\
2005 & 886,1 \\
2006 & 1910,0 \\
\hline $\mathrm{gl}=8 ; \alpha=0,01 ; \chi^{2}$ crítico $=20,090 ;{ }^{*} \mathrm{p}<0,01$ \\
\hline
\end{tabular}




\section{Tabela 4}

\section{Teste de homogeneidade entre a mídia e o governo - por dimensão}

\begin{tabular}{|lc|}
\hline Teste de homogeneidade & Valor da estatística $\chi^{2}$ \\
\hline Agronômica & 1170,5 \\
Ambiental & 2399,0 \\
Cultural & 939,9 \\
Econômica & 2075,8 \\
Geopolítica & 3346,8 \\
Legal & 1390,9 \\
Política & 2182,1 \\
Social & 594,3 \\
Tecnológica & 4265,1 \\
\hline gl $=9 ; \alpha=0,01 ; \chi^{2}$ crítico $=20,090 ;{ }^{*} p<0,01$ \\
\end{tabular}

Os valores obtidos para $\chi^{2}$ oferecem evidências suficientes para rejeitar a hipótese de que há homogeneidade nas proporções com a qual as dimensões macroambientais ocorrem nos documentos da mídia e do governo. Os períodos de maior homogeneidade entre a mídia e o governo foram os anos de 1997 $\left(\chi^{2}=100,9\right)$ e $2001\left(\chi^{2}=305,5\right)$. Quanto às dimensões mais homogêneas, foram: social $\left(\chi^{2}=594,3\right)$ e cultural $\left(\chi^{2}=939,9\right)$, justamente as dimensões com menor frequência de ocorrência, tanto na mídia quanto no governo. Contudo, nenhum desses resultados é estatisticamente significativo.

\section{Conclusões}

O objetivo deste artigo foi identificar as dimensões sob as quais o governo e a mídia do Brasil têm configurado o macroambiente para os biocombustíveis líquidos ao longo do tempo e testar a existência de similaridade entre o governo e a mídia na configuração do macroambiente. Para atingir o objetivo, foi realizada uma pesquisa documental, utilizando-se um conjunto de notícias veiculadas pela mídia escrita de circulação nacional e documentos oficiais do governo brasileiro.

Os resultados indicaram que a mídia e o governo do Brasil têm configurado o macroambiente para os biocombustíveis líquidos sob diferentes dimensões. Na mídia predominam as dimensões econômica, tecnológica, política e geopolítica, já no governo há a predominância das dimensões tecnológica e geopolítica, e a dimensão tecnológica apresenta destacada participação na configuração do macroambiente. 
Quando é levada em consideração a dinâmica da ocorrência relativa das dimensões macroambientais ao longo do tempo, percebe-se que há uma aproximação entre a mídia e o governo com relação aos aspectos tecnológicos do macroambiente para os biocombustíveis líquidos. Ao mesmo tempo que a dimensão tecnológica se firmou como a principal utilizada pelo governo, a partir de 2001 essa dimensão apresentou um crescimento na importância relativa com a mídia, refletindo uma tendência de aproximação na configuração do macroambiente, pelo menos no que diz respeito às questões tecnológicas.

Os resultados da análise de similaridade, do teste de aderência e do teste de homogeneidade entre a mídia e o governo indicaram: primeiro, existência de alguma similaridade nos aspectos do uso conjunto das dimensões para a configuração do macroambiente para os biocombustíveis líquidos. Observouse que as dimensões tecnológica e política são comuns à mídia e ao governo entre as três dimensões que ocorrem conjuntamente com maior frequência. A divergência está no fato de que a mídia utiliza os aspectos econômicos mais que os aspectos legais, que estão frequentemente presentes nos documentos do governo.

Os testes de aderência e homogeneidade revelaram que há diferença estatisticamente significativa nas frequências entre mídia e governo em pelo menos uma das dimensões. O nível de homogeneidade mais próximo entre mídia e governo foi verificado em 1997, e as dimensões com maior homogeneidade foram a social e a cultural.

Diante dos resultados encontrados no presente estudo, quais as implicações práticas e de ordem gerencial da análise macroambiental destinada ao planejamento estratégico das organizações em geral? E para os biocombustíveis em particular? No campo geral, o uso da mineração em textos, utilizada aqui, mostrou-se uma ferramenta com grande potencial de uso para a realização do escaneamento macroambiental. Esse procedimento analítico possibilita a transformação de um grande volume de informações, que se encontram em um formato textual, para dados quantitativos resumidos e utilizáveis. No caso da produção e do uso dos biocombustíveis líquidos especificamente, os resultados indicam que o macroambiente a partir do qual os agentes econômicos planejam suas ações e atividades pode variar ao longo do tempo e de acordo com as fontes de informações utilizadas. A variação temporal da configuração do macroambiente para os biocombustíveis líquidos reforça a necessidade de as organizações manterem práticas constantes de escaneamento ambiental como forma de identificar mudanças que possam afetar suas atividades.

Quanto ao uso de fontes de informação, são necessários estudos complementares para identificar o impacto de cada uma delas (mídia e gover- 
no) nas decisões das organizações. A literatura tem indicado que as fontes da mídia são mais usuais que os documentos oficiais de governo. Contudo, em uma atividade econômica emergente, como é a produção e o uso dos biocombustíveis líquidos, as decisões governamentais podem ser mais relevantes que as encontradas na mídia. A indicação de uma maior frequência de uso de documentos do governo para a análise macroambiental do planejamento estratégico é sustentada pelos resultados aqui,encontrados. Foi observado que a mídia brasileira tem sido pouco eficiente em transmitir as decisões do governo brasileiro ou, no mínimo, que governo e mídia ainda percebem o macroambiente para os biocombustíveis líquidos sob óticas divergentes.

\section{Referências bibliográficas}

AASHEIM, Chery; KOEHLER, Gary J. Scanning world wide web documents with the vector space model. Decision Support Systems, v. 42, p. 690-699, 2006.

AIZAWA, Akiko. An information-theoretic perspective of TF-IDF measures. Information, processing and management, v. 39, p. 45-65, 2003.

AUSTER, Ethel; CHOO, Chun Wei. Environmental scanning by CEOs in two Canadian industries. Journal of the American Society for Information Science, v. 44, n. 4, p. 194-203, 1993.

. How senior managers acquire and use information in environmental scanning. Information Processing \& Management, v. 30, n. 5, p. 607-618, 1994. BATES, Constance S. Mapping the environment: an operational environmental analysis model. Long Range Planning, v. 18, n. 5, p. 97-107, 1985.

BECKER, Lee B.; WHITNEY, D. Charles. Effects of media dependencies: audience assessment of government. Communication Research, v. 7, n. 1, p. 95-120, 1980.

BOIRAL, Olivier. Global warming: should companies adopt a proactive strategy? Long Range Planning, v. 39, p. 315-330, 2006.

CAMPONOVO, Giovanni. Conceptual models for designing information systems supporting the strategic analysis of technology environments. 2006. Thesis (PhD) -École des Hautes etudes Commerciales, Université de Lausanne, Lausanne, 2006.

CHAFFEE, Steven; FRANK, Stacey. How americans get political information: print versus broadcast news. The Annals of the American Academy of Political and Social Science, v. 546, n. 1, p. 48-58, 1996. 
CHOO, Chun Wei. Perception and use of information sources by chief executives in environmental scanning. LISR, v. 16, p. 23-40, 1994.

. The art of scanning the environment. Bulletin of the American Society for Information Science, p. 21-24, Feb./Mar. 1999.

; DETLOR, Brian; TURNBULL, Don. Information seeking on the web: an integrated model of browsing and searching. First Monday, v. 5, n. 2, Feb. 2000.

CHUNG, Y. M.; LEE, J. Y. A corpus-based approach to comparative evaluation of statistical term association measures. Journal of the American Society for Information Science and Technology, v. 52, n. 4, p. 283-296, 2001.

COSTA, Jorge. An empirically-based review of the concept of environmental scanning. International Journal of Contemporary Hospitality Management, v. 7, n. 7, p. 4-9, 1995.

CRAWLEY, Catherine E. Localized debates of agricultural biotechnology in community newspapers: a quantitative content analysis of media frames and sources. Science Communication, v. 28, n. 3, p. 314-346, Mar. 2007.

DECKER, Reinhold; WAGNER, Ralf; SCHOLZ, Sören W. An internet-based approach to environmental scanning in marketing planning. Marketing Intelligence \&Planning, v. 23, n. 2, p. 189-199, 2005.

DILL, William R. Environment as an influence on managerial autonomy. Administrative Science Quarterly, v. 2, n. 4, p. 409-443, 1958.

EL WAKIL, Mohamed M. Introducing text mining. Cairo, University, 2002.

FAHEY, Liam; KING, William R.; NARAYANAN, Vadake K. Environmental scanning and forecasting in strategic planning - the state of the art. Long Range Planning, v. 14, p. 32-39, Feb. 1981.

p. 61-71, Aug. 1977.

. Environmental scanning for corporate planning. Business Horizons,

FERNEDA, Edilson; PRADO, Hércules A.; SILVA, Edilberto M. Text mining for organizational intelligence. ICEIS, p. 446-450, 2003.

FLEISHER, Graig S.; BENSOUSSAN, Babette E. Strategic and Competitive Analysis: methods and techniques for analyzing business competition. Upper Saddle River, NJ: Prentice Hall, 2002.

GAMSON, William A.; MODIGLIANI, Andre. Media discourse and public opinion on nuclear power: a constructionist approach. The American Journal of Sociology, v. 95, n. 1, p. 1-37, July 1989. 
GINTER, P. M.; DUNCAN, W. J.; Macroenvironmental analysis for strategic management. Long Range Planning, v. 23, n. 6, p. 91-100, 1990.

; CAPPER, S. A. Strategic planning for public health practice using macroenvironmental analysis. Public Health Reports, v. 106, n. 2, p. 134-141, Mar./Apr. 1991.

;

. Keeping strategic thinking in strategic planning: ma-

cro-environmental analysis in a state department of public health. Public Health, v. 106, p. 253-269, 1992.

HALE, Roger. Text mining: getting more value from literature resources. Drug Discovery Today, v. 10, n. 6, March 2005.

HALLIMAN, Charles. Business intelligence using smart techniques: environmental scanning using text mining. Houston, TX: Information Uncover, 2001.

HIPPNER, H.; RENTZMANN, R. Text mining. Informatik Spektrum, v. 29, n. 4, p. 287-290, 2006.

HOLLANDER, Barry A. Television news exposure and foreign affairs knowledge: a six-nation analysis. International Communication Gazette, v. 59, n. 2, p. 151-161, 1997.

JING, Li-Ping; HUANG, Hou-Kuan; SHI, Hong-Bo. Improved feature selection approach TF-IDF in text mining. In: INTERNATIONAL CONFERENCE ON MACHINE LEARNING AND CYBERNETICS, 1. Proceedings... Beijing, China, 2002, p. 944-946.

JOGARATNAM, Giri; LAW, Rob. Environmental scanning and information source utilizations: exploring the behavior of Hong Kong hotel and tourism executives. Journal of Hospitality \& Tourism Research, v. 30, n. 2, p. 170-190, May 2006.

JOHNSON, Gerry; SCHOLES, Kevan; WHITTINGTON, Richard. Explorating Corporate Strategy: text and cases. 7. ed. Harlow: Pearson, 2005.

KARANIKAS, Haralampos; THEODOULIDIS, Babis. Knowledge Discovery in Text and Text Mining Software, Centre for Research in Information Management, Department of Computation, UMIST, Manchester, UK, 2002. Disponível em: <www.crim. co.umist.ac.uk>. Acesso em: 26 abr. 2006.

KEEGAN, Warren J. Multinational scanning: a study of the information sources utilized by headquarters executives in multinational companies. Administrative Science Quarterly, v. 19, n. 3, p. 411-421, Sep. 1974.

LAU, Kin-Nam; LEE, Kam-Hon; HO, Ying. Text mining for the hotel industry. Cornell Hotel and Restaurant Administration Quarterly, v. 46, n. 3, p. 344-362, 2005. 
LEIDECKER, Joel K.; BRUNO, Albert V. Identifying and using critical success factors. Long Range Planning, v. 17, n. 1, p. 23-32, 1984.

LEONIDOU, Leonidas C. Finding the right information mix for the export manager. Long Range Planning, v. 30, n. 4, p. 572-584, 1997.

LIDDY, E. D. Text mining. Bulletin of the American Society for Information Science, Oct./Nov. 2000.

LIU, Shuhua. Business environment scanner for senior managers: towards active executive support with intelligent agents. Expert Systems with Applications, v. 15, p. 111-121, 1998.

; TURBAN, Efraim; LEE, Mathew K. O. Software agents for environmental scanning in electronic commerce. Information Systems Frontiers, v. 2, n. 1, p. 8598, 2000.

MERMIN, Jonathan. Television news and American intervention in Somalia: the myth of a media-driven foreign policy. Political Science Quarterly, v. 112, n. 3, p. 385-403, 1997.

MYERS, Kent. Technology for the environmental scanning process. Systemic Practice and Action Research, v. 12, n. 4, p. 409-424, 1999.

NGAMKROECKJOTI, Chittipa; JOHRI, Lalit M. Management of environmental scanning processes in large companies in Thailand. Business Process Management, v. 6, n. 4, p. 331-341, 2000.

PREBLE, J. F.; RAU, P. A.; REICHEL, A. The environment scanning practices of U.S. multinationals in the late 1980's. Management International Review, v. 28, n. 4, p. 4-14, 1988.

SILVA C. et al. Mining linguistically interpreted texts. In: INTERNATIONAL WORKSHOP ON LINGUISTICALLY INTERPRETED CORPORA, 5. Geneva, 2004. p. 1-4. Disponível em: <www.coli.uni-saarland.de/conf/linc-04/silva.pdf>. Acesso em: 26 abr. 2006.

SINGH, N.; HU, C.; ROEHL, W. S. Text mining a decade of progress in hospitality human resource management research: identifying emerging thematic development. Hospitality Management, v. 26, p. 131-147, 2007.

STRÖMBERG, David. Mass media and public policy. European Economic Review, v. 45, p. 652-663, 2001.

STUBBART, Charles. Are environmental scanning units effective? Long Range Planning, v. 13, n. 3, p. 139-145, 1982. 
TERRY, P. T. Mechanisms for environmental scanning. Long Range Planning, v. 10, p. 2-9, June 1977.

THOMAS, Philip S. Environmental analysis for corporate planning. Business Horizons, p. 27-38, Oct. 1974.

VAN GORP, Baldwin. The constructionist approach to framing: bringing culture back. In: Journal of Communication, v. 57, p. 60-78, 2007.

VINCENT, Richard C. A comparative study of WSIS news coverage in North American and European broadcast/satellite, newspaper and wire service sources, 2001-2005. International Association for Mass Communication Research. The American University in Cairo, Egypt, July 2006.

WALSH, Philip R. Dealing with the uncertainties of environmental change by adding scenario planning to the strategy reformulation equation. Management Decision, v. 43, n. 1, p. 113-122, 2005.

WEI, Chih-Ping; LEE, Yen-Hsien. Event detection from online news documents for supporting environmental scanning. Decision Support Systems, v. 36, p. 385-401, 2004. 